\title{
BAX EXPRESSION REMAINS UNCHANGED FOLLOWING ANTISENSE TREATMENT DIRECTED AGAINST BCL-2
}

\author{
Marvin Rubenstein, Ph.D. (1) \\ Courtney M. P. Hollowell, M.D. (2) \\ Patrick Guinan, M.D. (3)
}

Division of Cellular Biology, Hektoen Institute for Medical Research (1,3), the Division of Urology, Stroger Hospital of Cook County $(1,2,3)$, the Departments of Biochemistry (1) and Urology (1,3), Rush University Medical Center, Department of Urology, and the Department of Urology (3), University of Illinois at Chicago, Chicago, IL, 60612.

Reprints and correspondence should be directed to: Dr. Marvin Rubenstein, ChairmanDivision of Cellular Biology, Hektoen Institute for Medical Research, 2240 West Ogden Avenue, 2'nd floor, Chicago, IL 60612. Phone: 312-864-4621; Fax: 312-768-6010; email: DrMarv@Prodigy.net

Running title: Mono- and bispecific antisense oligonucleotides have comparable activity against bcl-2.

Key words: Prostate cancer; Bax; Bcl-2; Antisense oligonucleotides; Gene therapy 


\section{ABSTRACT}

Antisense oligonucleotides (oligos) have been evaluated in both in vivo and in vitro prostate cancer models. Although most contain a single mRNA binding site, our lab has also evaluated bispecific types directed towards two proteins. This study evaluates the inhibition of in vitro propagating LNCaP cells employing mono- and bispecific oligos directed against bcl-2 [the second binding site was directed against the epidermal growth factor receptor (EGFR)]. Employing RT-PCR, the expression of two apoptosis regulating proteins, bcl-2 and non-targeted bax, were then evaluated.

LNCaP prostate tumor cells were initially incubated for 24 hours in the presence of oligos $(6.25 \mu \mathrm{M})$ directed against bcl-2 and compared to lipofectin containing controls. Comparable and significant growth inhibition was produced by both mono- and bispecific forms. Employing RT-PCR to determine the expression of bcl-2, we found that the greatest amount of mRNA suppression approached $100 \%$ for each oligo type: monospecific $\mathrm{MR}_{4}$ (directed only against bcl-2), 100\%; and bispecifics $\mathrm{MR}_{24}$ and $\mathrm{MR}_{42}$, $86 \%$ and $100 \%$ respectively. We conclude, based upon both inhibition of in vitro growth and bcl-2 expression, that bispecific antisense oligos directed against EGFR and bcl-2 mRNAs are at least as effective as a monospecific directed solely towards bcl-2.

In an effort to determine a compensatory response by cells evading apoptosis in the presence of bcl-2 suppression, the levels of mRNA encoding the non-targeted apoptosis activating protein bax were evaluated. Non-targeted protein suppression by these bispecifics has previously been demonstrated against prostate specific membrane antigen (PSMA). However, in contrast to effects against bcl-2 and PSMA, no significant alteration in bax expression was produced by either oligo type. 
In LNCaP cells, bcl-2 suppression does not influence bax expression and, at least for this protein, there is no compensatory change in bax expression regulating apoptosis at this level. Identifying changes in the expression of proteins which regulate apoptosis is important if gene therapy targets bcl-2. 


\section{INTRODUCTION}

Antisense oligonucleotides (oligos) have been employed against prostate cancer models in both in vivo and in vitro systems. Most specifically target a single gene product, although some may affect others which share sequence homology. For the treatment of prostate cancer, suppression targets have included protein growth factors, androgens (oligos were directed against 5-alpha reductase), receptors which bind either of these stimulating factors, inhibitors of apoptosis (bcl-2 [directly an inhibitor] and clusterin [an inhibitor of activated bax, which is a promoter]) and various oncogenes. Oligos provide a specific, relatively non-toxic method for the translational arrest of protein synthesis through a variety of mechanisms which include degradation of annealed mRNA:oligo duplexes by RNase H (1), protein binding interactions and DNA triplex formation (2,3). Most measurements of oligo activity quantitate inhibition of in vitro growth, however, more direct methods use the polymerase chain reaction (PCR) to measure suppression of protein specific mRNA.

Since most tumors are characterized by enhanced expression of many proteins, we attempted to increase oligo efficacy by first suggesting (4) and subsequently evaluating bispecific derivatives (5-9) containing two binding sites on a single DNA strand. This study evaluates the inhibition of in vitro propagating LNCaP cells employing mono- and bispecific oligos directed against bcl-2 [the second binding site was directed against the epidermal growth factor receptor (EGFR)]. EGFR was included as a second target in our bispecifics because both EGF (epidermal growth factor) and TGF- $\alpha$ (transforming growth factor-alpha) ligands are key regulators of prostate cancer growth $(10,11)$ and bind to

EGFR. Previously, we demonstrated that mono-specific antisense oligos directed 
towards EGFR expression significantly inhibited cell growth, but such changes were not related to alterations in mRNA content (12).

Bispecific oligos can be directed towards non-sequence related proteins, including those from different pathways. It's naïve to believe that cancer cell growth can be controlled by oligos through knockdown of a single gene product. Instead, multiple genes must be down regulated and it would be useful if multiple activities could be place onto a single entity (oligo). This bispecific approach differs from other investigators employing either multispecific oligos (like those) targeting bcl-2 and bcl-xL genes (which share sequence homology) (13) or the OGX-225 oligo which similarly targets (three) structurally related insulin like growth factor binding proteins (14). In proof of concept, bispecifics have demonstrated inhibition of in vitro cell growth when directed against genes involved in a single autocrine loop (5) as well as when directed towards proteins of different growth regulatory paths (6-9).

We now evaluate the effect of a single mono- and two bispecific oligos directed against bcl-2 employing RT-PCR measuring the expression of both targeted bcl-2 and untargeted bax. Both proteins regulate apoptosis, in an opposing manner; bcl-2 is inhibitory, while activated bax stimulates the process. It is believed that among the heterogeneous cells found within a tumor, those which have enhanced bcl-2 and/or reduced bax expression are selected to evade apoptosis; making them potential targets for gene therapy.

In addition to bcl-2 and bax, apoptosis in prostate cancer cells is further regulated by anti-apoptotic bcl-xL and various caspases (15). Altered expression is often associated with effective therapy. When LNCaP cells are treated with Finasteride, 
increased bax and decreased bcl-xL expression is found (15). For patients treated with brachytherapy, apoptotic induction and bcl-2 over expression is correlated with treatment outcome: Those with treatment failure had significantly elevated bcl-2 (16). In LNCaP and DU145 cells, treatment with amygdalin similarly decreases bcl-2 while increasing both bax and caspase-3 expression as apoptotic cell death is induced (17).

However, following gene specific therapy, non-targeted (and non-sequence related) proteins can have their expression altered by compensatory downstream effects. Furthermore the expression of additional proteins (caspase-3 [18]) and even the apoptotic process itself (in prostate epithelial cells [19]) can be dependent upon the ratio between opposite acting proteins (bcl-2 and bax). The effect upon non-targeted, unrelated, proteins has already been demonstrated with these oligos. Both bispecifics, evaluated here, significantly suppressed the expression of prostate specific membrane antigen (PSMA in LNCaP cells, while no suppression was produced by the monospecific oligo targeting only bcl-2. It was suggested that PSMA suppression (not seen against prostate specific antigen [PSA]) could be attributed to a unique double strand conformation produced in these bispecific forms which mimick that of poly I:C (an interferon inducer) (20). When induced, interferon stimulates expression of cell surface antigens including MHC class I (21) and receptors which bind tumor necrosis factor-alpha (TNF- $\alpha$ ) (22). Additional evaluations of compensatory changes in non-targeted protein expression are currently in progress. If gene therapy is to be effective when directed against bcl-2, compensatory changes which compromise the effectiveness of the desired suppression must be identified. If an additional gene activity must be suppressed monoor bispecific oligos (directed against bcl-2 and this second apoptosis inhibitory protein) 
can again be employed. 


\section{METHODS}

\section{Oligonucleotides}

Oligos (mono- or bispecific) were purchased from Eurofins MWG Operon (Huntsville, AL). Each was phosphorothioated on three terminal bases at 5' and 3' positions. Stock solutions were made to a final concentration of $625 \mu \mathrm{M}$ in sterile Dulbecco PBS.

\section{Base Sequences}

Each oligo contained at least one CAT sequence and targeted the area adjacent to the AUG initiation codon for mRNA encoding the respective targeted protein (bcl-2 or EGFR).

$\mathbf{M R}_{\mathbf{4}}$ (monospecific targeting bcl-2): T-C-T-C-C-C-A-G-C-G-T-G-C-G-C-C-A-T

$\mathbf{M R}_{24}$ (bispecific targeting EGFR/bcl-2): G-A-G-G-G-T-C-G-C-A-T-C-G-C-T-G-C-T-C- T-C-TC-C-C-A-G-C-G-T-G-C-G-C-C-A-T

$\mathbf{M R}_{42}$ (bispecific targeting bcl-2/EGFR): T-C-T-C-C-C-A-G-C-G-T-G-C-G-C-C-A-T-G-A-G-GG-T-C-G-C-A-T-C-G-C-T-G-C-T-C

\section{Cell Culture}

LNCaP cells were grown in RPMI 1640 supplemented with $10 \%$ bovine serum, $1 \%$ L-glutamine and $1 \%$ penicillin/streptomycin in a $5 \% \mathrm{CO}_{2}$ incubator. Log phase cells were harvested using EDTA/Trypsin and equally distributed into $75 \mathrm{~cm}^{2}$ flasks (Corning, NY). At intervals media was either supplemented or replaced with fresh.

\section{Determination of Growth}

Four days prior to the addition of oligos 1 X $10^{4} \mathrm{LNCaP}$ cells were added, in a total $200 \mu \mathrm{l}$ volume of media, to each depression of a 96 well plate and incubated at $37^{\circ} \mathrm{C}$ in a $5 \% \mathrm{CO}_{2}$ incubator. On the day of transfection the following solutions were prepared: 
A) $1 \mu 1$ of buffer containing either oligo or a diluent was added to $50 \mu 1$ of OPTIMEM and gently mixed. One dilution was made for each well.

B) $1 \mu \mathrm{l}$ of Lipofectin was diluted in $50 \mu \mathrm{l}$ of OPTI-MEM and mixed gently for 5 minutes at room temperature.

C) ODN dilutions were mixed with $50 \mu \mathrm{l}$ of Lipofectin and gently mixed for 20 minutes at room temperature.

D) $\quad 100 \mu \mathrm{l}$ of the Lipofectin and ODN mixture was added to $100 \mu \mathrm{l}$ of F-12 or RPMI medium and mixed.

Cells were incubated for $24-48 \mathrm{hrs}$ before solutions were aspirated and reincubated for an additional $48 \mathrm{hrs}$ in $200 \mu \mathrm{l}$ of media. Cell counts were determined following the addition of WST-1 reagent to each well, and after 2 hrs the color intensity was measured by a micro-plate reader at a wavelength of $450 \mathrm{~nm}$, using a reference of $650 \mathrm{~nm}$. Values obtained were determined after the subtraction of paired blank samples from the experimental wells and were multiplied by a constant to give whole integers for analysis. Microsoft Excel software was utilized to calculate means and standard deviations and Students $t$ tests were used to determine significance.

\section{Oligo Treatment Prior to PCR}

Fours days prior to oligo addition, when cell density approached $75 \%$ confluence, $10 \mathrm{ml}$ of fresh media was added. Cells were incubated for an additional 3 days before 5 $\mathrm{ml}$ of media was replaced with fresh the day before oligos were added. $100 \mu \mathrm{l}$ of stock oligos were added to bring the final concentration to $6.25 \mu \mathrm{M}$. Incubation proceeded for an additional 24 hours in the presence or absence of monospecific $\mathrm{MR}_{4}$, or the $\mathrm{MR}_{24}$ and $\mathrm{MR}_{42}$ bispecifics. 


\section{RNA Extraction}

Following treatment, media was removed, a single $\mathrm{ml}$ of cold $\left(4^{\circ} \mathrm{C}\right) \mathrm{RNAzol} \mathrm{B}$ was added to each $75 \mathrm{~cm}^{2}$ culture flask and the monolayer lysed by repeated passage through a pipette. All procedures were performed at $4^{\circ} \mathrm{C}$. The lysate was removed, placed in a centrifuge tube to which $0.2 \mathrm{ml}$ of chloroform was added, and shaken. The mixture stayed on ice for $5 \mathrm{~min}$, was spun at 12,000 $\mathrm{g}$ for $15 \mathrm{~min}$, and the upper aqueous volume removed and placed in a fresh tube. An equal volume of isopropanol was added, the tube shaken, and allowed to stay at $4^{\circ} \mathrm{C}$ for $15 \mathrm{~min}$ before similar centrifugation to pellet the RNA. The supernatant was removed, the pellet washed in a single $\mathrm{ml}$ of $75 \%$ ethanol, then spun for $8 \mathrm{~min}$ at $7500 \mathrm{~g}$. The ethanol was pipetted off and the formed pellet air dried at $-20^{\circ} \mathrm{C}$.

\section{RNA Quantitation}

RNA was resuspended in $250 \mu \mathrm{l}$ of DEPC treated $\mathrm{H}_{2} \mathrm{O}$, and quantitated using a Qubit florometer and Quant-iT RNA assay kit (Invitrogen). DEPC is an inhibitor of RNase activity.

\section{RT-PCR}

Extracted RNA was diluted to $40 \mu \mathrm{g} / \mu \mathrm{l}$ in DEPC treated water. $1 \mu \mathrm{l}$ of this RNA was added to $1 \mu \mathrm{l}$ of both sense and antisense primers (forward and reverse sequences) for human actin (used as a control) or $2 \mu \mathrm{l}$ of combined primers for bcl-2 or bax. From a kit purchased from Invitrogen the following reactants were added for RT-PCR: $25 \mu 1$ of $2 \mathrm{X}$ reaction mixture, $2 \mu 1$ SuperScript III RT / platinum Taq mix, tracking dye, and $\mathrm{MgSO}_{4}$ ( $3 \mu \mathrm{l}$ of a stock concentration of $5 \mathrm{mM}$, used for bcl-2 and bax vials only). DEPC treated water was added to yield a final volume of $50 \mu \mathrm{l}$. As a control for RT-PCR product 
production, human actin expression was tested in RNA extracted from HeLa cells which was provided in a kit purchased from Invitrogen. RT-PCR was performed for 2 X 25 cycles using the F54 program in a Sprint PCR Thermocycler

\section{Primers:}

\section{Actin}

Forward primer sequence: 5' CAA ACA TGA TCT GGG TCA TCT TCT C 3'

Reverse primer sequence: 5' GCT CGT CGT CGA CAA CGG CTC

PCR product produced was 353 base pairs in length

\section{Bcl-2}

Forward primer sequence: 5' GAG ACA GCC AGG AGA AAT CA 3'

Reverse primer sequence: 5' CCT GTG GAT GAC TGA GTA CC 3'

PCR product produced was 127 base pairs in length.

\section{Bax}

Forward primer sequence: 5' GCT GGA CAT TGG ACT TCC TC 3'

Reverse primer sequence: 5' CTC AGC CCA TCT TCT TCC AG 3'

PCR product produced was 168 base pairs in length.

\section{DETECTION AND QUANTITATION OF PRODUCT}

\section{Agarose Gel Electrophoresis}

$1.5 \%$ agarose gels were prepared in a $50 \mathrm{ml}$ volume of TBE buffer (1X solution: $0.089 \mathrm{M}$ Tris borate and $0.002 \mathrm{M}$ EDTA, $\mathrm{pH} 8.3$ ), containing $3 \mu \mathrm{l}$ of ethidium bromide $(10 \mathrm{mg} / \mathrm{ml}$ in $1 \mathrm{X}$ Tris borate buffer) in a Fisher Biotest electrophoresis system. Samples were run for 2 hours at a constant voltage of 70 using a BioRad 1000/500 power supply source. To locate the amplified PCR product, $3 \mu \mathrm{l}$ of a molecular marker which contained 
a sequence of bases in 100 base pair increments (Invitrogen) as well as $2 \mu 1$ of a sucrose based bromphenol blue tracking dye were run in each gel. For actin product localization, the tracking dye was included in each sample run; for the bcl-2 product the tracking dye was run separately.

\section{Quantitation}

Gels were visualized under UV light and photographed using a Canon 800 digital camera. Photos were converted to black and white format and bands quantitated using Mipav software provided by NIH. 


\section{RESULTS}

\section{Cell Culture Experiments}

LNCaP cells were incubated with $\mathrm{MR}_{4}, \mathrm{MR}_{24}$ and $\mathrm{MR}_{42}$ and compared to lipofectin containing controls (Figure 1). In an initial experiment each oligo significantly inhibited the growth of LNCaP cells: $\mathrm{MR}_{4}$ by $23.8 \%(\mathrm{p}=0.0004) ; \mathrm{MR}_{24}$ by $31.2 \%(\mathrm{p}<$ $0.001)$; and $\mathrm{MR}_{42}$ by $31.7 \%(\mathrm{p}<0.001)$.

In a repeat experiment $\mathrm{LNCaP}$ cells were similarly incubated and compared to lipofectin containing controls. Bispecific oligos $\mathrm{MR}_{24}$, and $\mathrm{MR}_{42}$ produced significant respective inhibitions of $49.5 \%(\mathrm{p}<0.001)$ and $56.8 \%(\mathrm{p}<0.001)$, and were at least as effective as the monospecific $\mathrm{MR}_{4}$ directed only towards bcl-2 in the inhibition of in vitro cell growth.

\section{RT-PCR Experiments}

When photographs of the identified product bands were scanned on agarose gels and quantitated using Mipav software, in a series of runs, the greatest expression of bcl-2 was always found in untreated LNCaP cells. Those treated with oligos, whether mono- or bispecific, produced bands which indicated obvious (to the naked eye) suppression. Figure 2 provides an example of one such band (actin) suitable for scanning and quantitation. The molecular weight markers shown in the left column are (in 100 base pair increments) 600 and 100 base pairs (from top to bottom). The band visualized between molecular markers of 300 and 400 base pairs is the expected 353 base pair human actin PCR product. 


\section{Bcl-2 Expression}

LNCaP cells incubated for 24 hours in the presence of $6.25 \mu \mathrm{M}$ of oligos demonstrated a suppression of bcl-2 expression, and support the finding of comparable biologic activity of both mono- and bispecific oligos seen in in vitro cell inhibition experiments. For each oligo evaluated, the greatest amount of suppression measured approached $100 \%$, for the mono-specific $\mathrm{MR}_{4}$; and for the bispecifics $\mathrm{MR}_{24}$ and $\mathrm{MR}_{42}$, $86 \%$ and $100 \%$, respectively. Suppression was found in both repeat PCR runs with bcl-2 primers, as well as in repetitive agarose gel quantifications. Figure 3 presents a bcl-2 product band in the expected 127 base pair region which in this run was inhibited $23 \%$ by treatment with the monospecific $\mathrm{MR}_{4}$, and $86 \%$ and $74 \%$, respectively by bispecifics $\mathrm{MR}_{24}$ and $\mathrm{MR}_{42}$, as measured by Mipav software.

Based upon both inhibition of cell growth and bcl-2 expression we concluded that bispecific antisense oligos directed against EGFR and bcl-2, regardless of their tandem orientation, are at least as effective as the monospecific type directed solely towards bcl2. The addition of a second mRNA binding site (directed towards EGFR) to these oligos does not prevent activity at the initial site specific for bcl-2.

\section{Bax Expression}

Comparable amounts of extracted RNA from LNCaP cells treated with either mono- or bispecific oligos directed against bcl-2 (and EGFR in the bispecifics). This RNA was evaluated by RT-PCR using primers directed against bax. A representative band for bax is presented in Figure 4 and appears immediately below the marker representing 200 base pairs. 
When background intensity was subtracted, the relative intensity of the bands corresponding to bax representing cells treated with $\mathrm{MR}_{4}, \mathrm{MR}_{24}$ and $\mathrm{MR}_{42}$ compared to controls were $-5.74 \pm 16.9,5.54 \pm 19.2$, and $-15.34 \pm 32.9$. These results were pooled from both duplicate PCR runs and gels and indicated that no significant differences in expression were found, compared to that seen with bcl-2. 


\section{DISCUSSION}

Gene therapy for cancer is a complex process requiring multiple pathways (and their regulatory proteins) be simultaneously regulated. For gene products which are over expressed, methods to suppress their activities have been developed, including the use of antisense oligos. For the treatment of prostate cancer, some (produced by Oncogenex Pharmaceuticals) have reached clinical trials (OGX-011), while others remain in preclinical development (OGX-225). Often administered in combination with traditional chemotherapy, these oligos target proteins, like bcl-2, clusterin (OGX-011 in Phase II testing), heat shock protein 27 (OGX-427) or insulin growth factor binding proteins (OGX-225). Some represent efforts to restore tumor apoptosis by eliminating those proteins associated with treatment resistance. For those genes diminished or lacking in expression, methods for replacement must be further developed, like PTEN gene transfection to restore effective radiation (23) or chemotherapy sensitization (24) to prostate cancer cells while suppressing bcl-2 activity (24).

An antisense strategy can accomplish translational arrest and a cocktail of antisense oligos, could theoretically shut down many over expressed genes. Rather than employ a pool of separate oligos, each targeting a different gene (25), it would be desirable if several activities could be regulated by single, multi-specific, oligos, like those reported by other investigators $(13,14)$. However, these oligos target genes which share a region of sequence homology, and have similar biologic activity. What we define as bispecific oligos are those which target more than one protein (unrelated in sequence), and capable of binding mRNA which encodes proteins from even different growth regulatory pathways. 
In this study we evaluated the effect of oligo mediated growth suppression on two regulators of apoptosis: bcl-2 (an inhibitor) and bax (a promoter). However, both monoand bispecific antisense forms used here specifically targeted bcl-2. In contrast to the suppression produced solely by the bispecifics against the non-targeted PSMA (20), we found no differential effect between mono or bispecific forms: Both suppressed the targeted bcl-2 and had no significant effect against the expression of bax. PSMA was evaluated because, as a cell surface antigen, it is increasingly being targeted for specific delivery of anti-cancer agents; most recently by a bivalent (antisense-like) PSMA binding aptamer-siRNA transcript targeting eukaryotic elongation factor-2 mRNA (26). Enhanced PSMA expression on prostate cancer cells, following suitable bispecfic oligo administration, would not only allow increased delivery of chemotherapeutics but also targeting by cytotoxic $\mathrm{T}$ cells.

In nature, tumors are heterogenous and during the process of malignant transformation possibly hundreds of genes are in some way altered in expression. However, an early event in tumor evolution often includes evasion of apoptosis. This "programmed" process clears the body of altered (transformed) or damaged cells. It is highly regulated, and involves many proteins being synthesized, recognized (via receptors) or otherwise interacting or activating each other. The overall efficiency of the process is regulated by many of these proteins, acting in multiple pathways, with individual pathways often regulated by the overall ratio of stimulatory or inhibitory influences. Clinically, many gene therapy protocols direct their activity towards suppression of the inhibitory products, particularly bcl-2. Some even include antisense strategies, and oligos have been included in protocols meant to restore apoptosis 
associated with chemotherapy (13) or radiation treatment (27) including that against prostate cancer $(28)$.

Inhibition of the apoptotic process is also related to the establishment of cancer cell immortality. While telomerase activity is the enzyme most associated with immortality, its activity is related to that of bcl-2 and in colorectal cancers is increased in cases having the greatest bcl-2 expression (29).

For gene therapy to be successful, any (compensatory) effects on untargeted genes must be identified. This is particularly important when translational inhibitors (including any type of antisense; first, second generation or siRNA derivatives) are administered. Tumors are very adaptable and compensatory mechanisms which negate or substantially interfere with the original therapy have not been fully identified. When identified, one way to suppress multiple gene activities could employ bispecific oligos, similar to those evaluated in these studies, or a proposed multispecific form (30). Additional studies are underway to identify altered expressions in other proteins associated with apoptosis. Identifying changes in these proteins and how tumors continue to evade apoptotic pathways is important if gene therapy is employed targeting bcl-2.

\section{Acknowledgments:}

The Cellular Biology laboratory at the Hektoen Institute is supported, in part, by the Blum Kovler Foundation, the Cancer Federation, Safeway/Dominicks Campaign for Breast Cancer Awareness, Lawn Manor Beth Jacob Hebrew Congregation, the Max Goldenberg Foundation, the Sternfeld Family Foundation, and the Herbert C. Wenske Foundation. 


\section{REFERENCES}

1) Walder RY, Walder JA. Role of RNase H in hybrid-arrested translation by antisense oligonucleotides. Proc Natl Acad Sci USA 1988; 85: 5011-5015.

2) Felsenfeld G, Miles HT. Formation of a three-stranded polynucleotide molecule. J Amer Chem Soc 1957; 79: 2023-2024.

3) Durland RH, Kessler DJ, Hogan M. Antiparallel triplex formation at physiological pH. In: Prospects for Antisense Nucleic Acid Therapy of Cancer and AIDS. E. Wickstrom (Ed.), Wiley-Liss, New York, 1991, 219-226.

4) Rubenstein M, Tsui $P$, Guinan P. Construction of a bispecific antisense oligonucleotide containing multiple binding sites for the treatment of hormone insensitive prostate tumors. Med Hypotheses 2005; 65: 905-907.

5) Rubenstein M, Tsui P, Guinan P. Bispecific antisense oligonucleotides with multiple binding sites for the treatment of prostate tumors and their applicability to combination therapy. Methods Find Clin Pharmacol 2006; 28: 515-518.

6) Rubenstein M, Tsui P, Guinan P. Combination chemotherapy employing bispecific antisense oligonucleotides having binding sites directed against an autocrine regulated growth pathway and bcl-2 for the treatment of prostate cancer. Med Oncol 2007; 24:372378.

7) Rubenstein, M., Tsui, P., Guinan, P. Multigene targeting of signal transduction pathways for the treatment of breast and prostate tumors. Comparison between combination therapies employing bispecific oligonucleotides with either Rapamycin or Paclitaxel. Med Oncol 2009; 26:124-130.

8) Rubenstein M, Tsui P, Guinan P. Bispecific antisense oligonucleotides having 
binding sites directed against an autocrine regulated growth pathway and bcl-2 for the treatment of prostate tumors. Med Oncol 2007; 24:189-196.

9) Rubenstein M, Tsui P, Guinan P. Treatment of MCF-7 breast cancer cells employing mono- and bispecific antisense oligonucleotides having binding specificity towards proteins associated with autocrine regulated growth and bcl-2. Med Oncol 2008; 25: 182-186.

10) Chen W, Yan C, Pu J, Hou J, Wen D, Guo Z. Regulation of EGF-receptor expression by TGFalpha in human prostate androgen-unresponsive cancer cells. Zhonghua Nan Ke Хие 2006; 10: 595-597.

11) Seth D, Shaw K, Jazayeri J, Leedman PJ. Complex post-transcriptional regulation of EGF-receptor expression by EGF and TGF- $\alpha$ in human prostate cancer cells. Brit $J$ Cancer 1999; 80: 657-669.

12) Rubenstein M, Mirochnik Y, Bremer E, George D, Freilich L, Guinan P. Inhibitory effect of antisense oligonucleotides targeting epidermal growth factor receptor may not be related to changes in mRNA levels in human prostate carcinoma cells. Proceedings AACR 2002; 43: 590a.

13) Yamanaka K, Miyake H, Zangemeister-wittke U, Jansen B, Gleave M. Novel bispecific antisense oligonucleotides inhibiting both Bcl-2 and Bcl-xL expression induce apoptosis and enhance chemosensitivity in human androgen-independent prostate cancer cells. Proceedings AACR 2004; 45:Abstract \#2930.

14) Takahara K, Muramaki M, Li D, Cox ME, Gleave ME. Insulin-like growth factorbinding protein-5 (IGFBP5) supports prostate cancer cell proliferation. J Urol 2009; 181: $184 \mathrm{a}$. 
15) Golbano JM, Lóppez-Aparicio P, Recio MN, Pérez-Albarsanz MA. Finasteride induces apoptosis via Bcl-2, Bcl-xL, Bax and caspase-3 proteins in $\mathrm{LNCaP}$ human prostate cancer cell line. Int J Oncol 2008; 32: 919-924.

16) Szostak MJ, Kaur P, Amin P, Jacobs SC, Kyprianou N. Apoptosis and bcl-2 expression in prostate cancer: Significance in clinical outcome after brachytherapy. $J$ Urol 2001; 165: 2126-2130.

17) Chang H-K, Mal-Soon S, Hye-Young Y, Jin-Wood L, Young-Sick K, Myoung-Hwa L, Jullia K, Khae-Hawn K, Chang-Ju K. Amygdalin induces apoptosis through regulation of bax and bcl-2 expressions in human DU145 and LNCaP prostate cancer cells. Biol Pharm Bull 2006; 29: 1597-1602.

18) Salakou, S., Kardamakis, D., Tsamandas, A.C., Zolota, V., Apostolakis, E., Tzelepi, V., Papathanasopoul, P., Bonikos, D.S., Papapetropoulos, T., Petsas, T. and Dougenis, D.: Increased bax.bcl-2 ratio up-regulates caspase-3 and increases apoptosis in the thymus of patients with myasthenia gravis. In Vivo 2007; 21: 123-132.

19) Perlman, H., Zhang, X., Chen, M.W., Walsh, K., Buttyan, R.: An elevated bax/bcl-2 ratio corresponds with the onset of prostate epithelial cell apoptosis. Cell Death and Differentiation 1999; 6: 48-54.

20) Rubenstein, M., Hollowell, CMP, Guinan, P.: Increased Prostate Specific Membrane Antigen Expression in LNCaP Cells Following Treatment with Bispecific Antisense Oligonucleotides Directed Against bcl-2 and EGFR. (In Press: Medical Oncology) 21) Basham TY, Nickoloff BJ, Merigan TC and Morhenn VB. Recombinant gamma interferon induced HLA-DR expression on cultered human keratinocytes. J Invest Derm 
1984; 83: 88-90.

22) Msujimoto M, Yip YK and Vilcek J. Interferon-gamma enhances expression of cellular receptors for tumor necrosis factor. J Immunol 1986; 136: 2441-2444. 23) Virus Weekly: June 1, 2004: http://www.highbeam.com/doc/1G1-117341301.html 24) Huang H, Cheville JC, Pan Y, Roche PC, Schmidt LJ, Tindall DJ. PTEN induces chemosensitivity in PTEN-mutated prostate cancer cells by suppression of bcl-2 expression. J Biol Chem 2001; 276: 38830-388306.

25) Rubenstein M, Mirochnik Y, Chow P, Guinan P. Antisense oligonucleotide intralesional therapy of human PC-3 prostate tumors carried in athymic nude mice. $\mathrm{J}$ Surg Oncol 1996; 62:194-200.

26) Wullner U, Neef I, Eller A, Kleines M, Tur MK, Barth S. Cell-specific induction of apoptosis by rationally designed bivalent aptamer-siRNA transcripts silencing eukaryotic elongation factor 2. Curr Cancer Drug Targets 2008: 8; 554-565.

27) Yip KW, Mocanu JD, Au PY, Sleep GT, Busson D, Yeh P, Gilbert WC, O’Sullivan R, Gullane B, Bastianutto C, Liu FF. Combination bcl-2 antisense and radiation therapy for nasopharyngeal cancer. Clin. Cancer Res 2005; 11: 8131-8144.

28) $\mathrm{Mu} Z$, Hachem P, Pollack A. Antisense bcl-2 sensitizes prostate cancer cells to radiation. The Prostate 2005; 65: 331-340.

29) Lida A, Yamaguchi A, Hirose K. Telomerase activity in colorectal cancer and its relationship to bcl-2 expression. J Surg Oncol 2000; 73: 219-223.

30) Rubenstein M, Anderson KM, Tsui P, Guinan P. Synthesis of branched antisense oligonucleotides having multiple specificities. Treatment of hormone insensitive prostate cancer. Med Hypoth 2006; 67:1375-1380. 
FIGURE 1

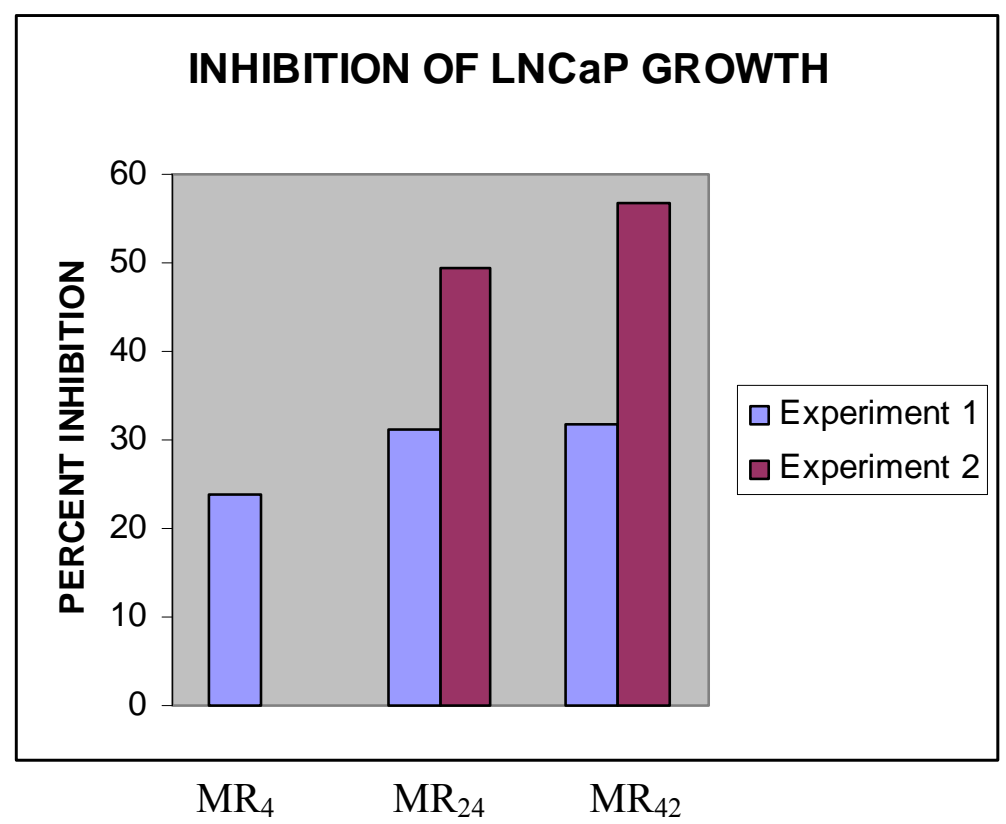

Inhibition of in vitro growth of LNCaP cells by mono- and bispecific oligos. 
FIGURE 2

Expression of Actin on Agarose Gel

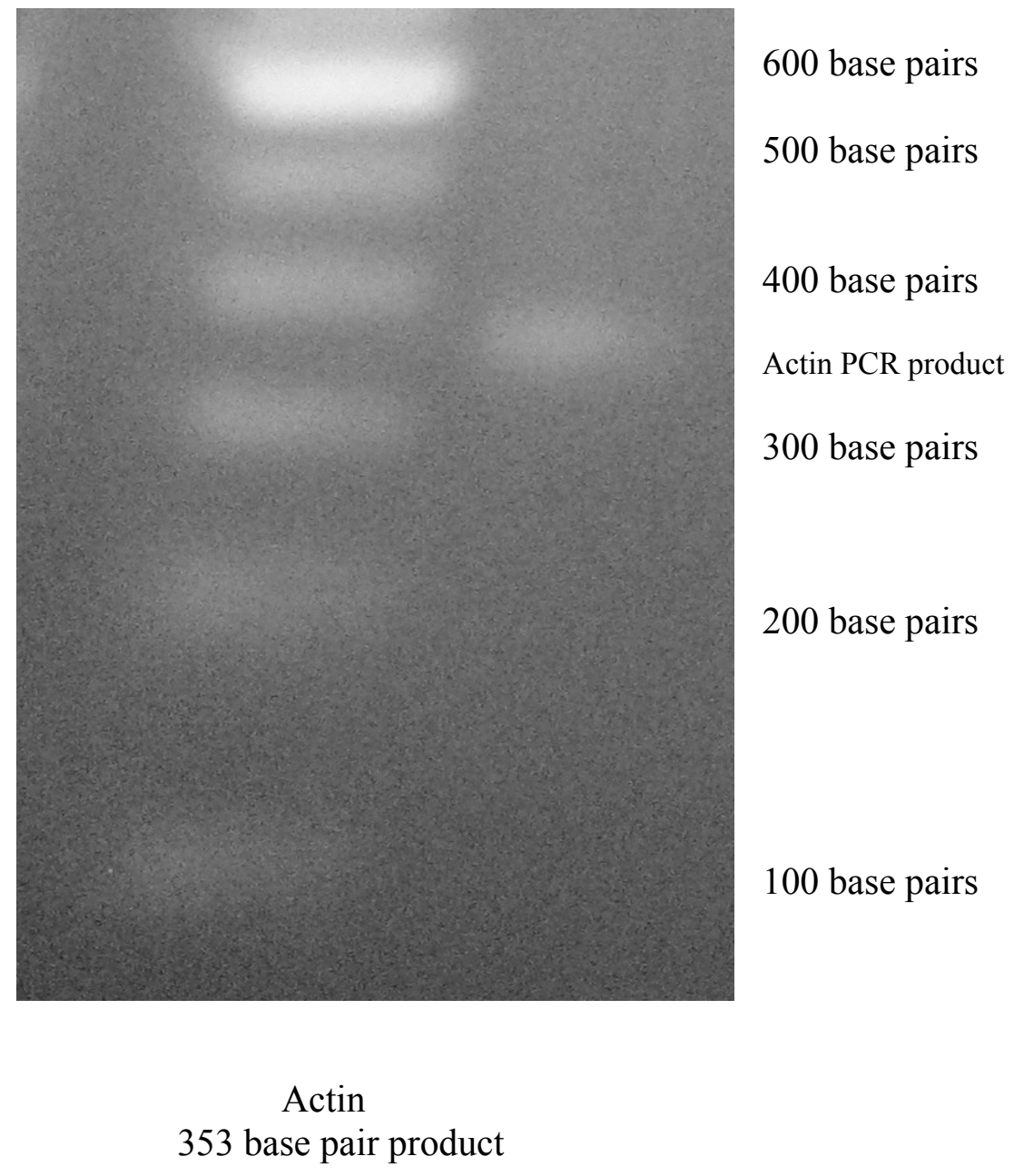


FIGURE 3

Expression of bcl-2 on Agarose Gel

200 base pairs

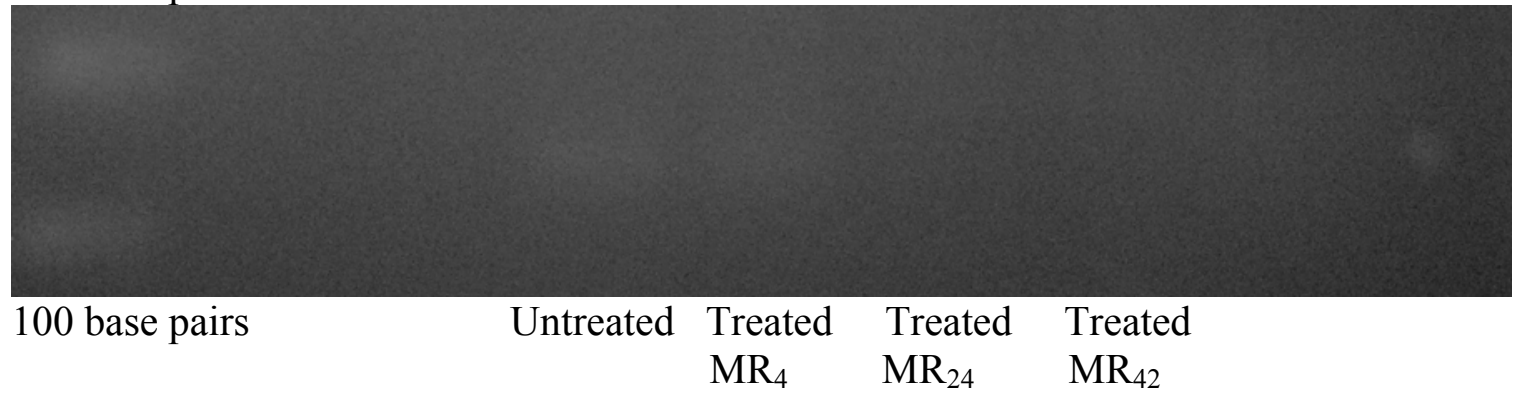

Bcl-2 127 base pair product 
FIGURE 4

Expression of Bax on Agarose Gel

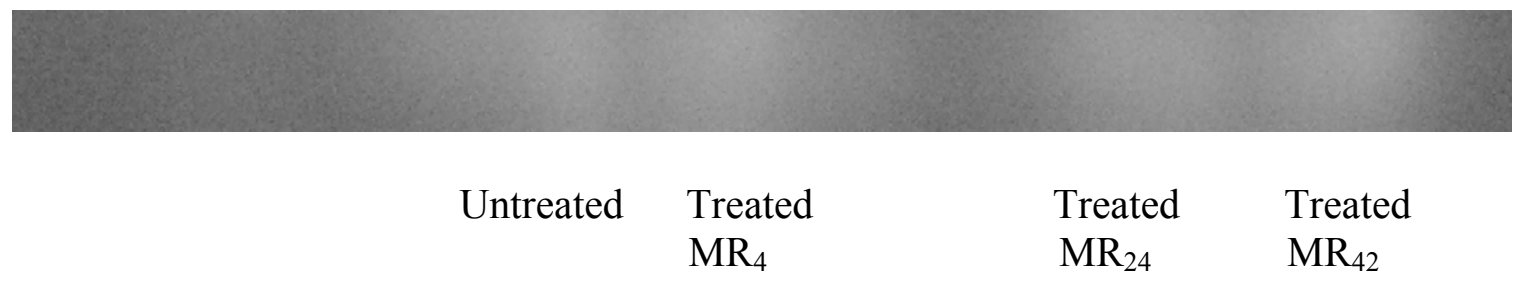

Bax is a 168 base pair product 